\title{
ASPECTOS CIENTÍFICOS E TECNOLÓGICOS DO EMPREGO DE CULTURAS PROBIÓTICAS NA ELABORAÇÃO DE PRODUTOS LÁCTEOS FERMENTADOS: REVISÃO
}

\author{
CRISTIANO AUGUSTO BALLUS* \\ VERA MARIA KLAJN** \\ MÁRCIO FERRAZ CUNHA*** \\ MARLON LEONARDO DE OLIVEIRA $A^{\star \star \star *}$ \\ ÂNGELA MARIA FIORENTINI ${ }^{\star \star \star \star *}$
}

\begin{abstract}
O presente trabalho, mediante revisão de literatura, teve como objetivo apresentar os efeitos benéficos que a ingestão de probióticos pode oferecer à saúde e os inúmeros aspectos científicos e tecnológicos fundamentais para a elaboração de produto lácteo probiótico. Abordou-se a utilização de bactérias ácido lácticas produtoras de exopolissacarídeos, bem como o desenvolvimento de novas classes de produtos funcionais envolvendo microrganismos probióticos em conjunto com compostos prebióticos (alimentos simbióticos). A seleção de microrganismo com propriedades probióticas exige a observação de três fatores principais: segurança, características funcionais e características tecnológicas. Portanto, a observação desses aspectos possibilitará a obtenção de produtos probióticos com a qualidade necessária e em sua máxima funcionalidade.
\end{abstract}

PALAVRAS-CHAVE: FERMENTAÇÃO; PROBIÓTICOS; PREBIÓTICOS; EXOPOLISSACARÍDEOS; ALIMENTOS FUNCIONAIS.

* $\quad$ Mestrando em Ciência de Alimentos, Universidade Estadual de Campinas (UNICAMP), Campinas, SP (e-mail: cristiano_ballus@yahoo.com.br).

** Mestre em Agroquímica, doutoranda em Ciência e Tecnologia Agroindustrial, Universidade Federal de Pelotas (UFPel), Pelotas, RS (e-mail: veraklajn@gmail.com).

*** Mestre em Alimentos e Nutrição, docente do Curso de Nutrição, Universidade de Uberaba (UNIUBE), Uberaba, MG (e-mail: marcio.cunha@uniube.br).

**** Bacharel em Química Industrial de Alimentos pela Universidade Regional do Noroeste do Estado do Rio Grande do Sul (UNIJUÍ), Santa Rosa, RS (e-mail: marlon-chupim@hotmail.com).

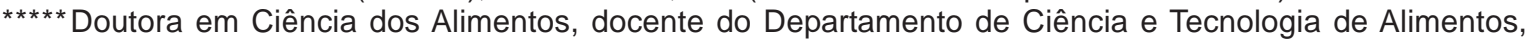
UFPel, Pelotas, RS (e-mail: angefiore@gmail.com). 


\section{INTRODUÇÃO}

A produção de leites fermentados, um dos procedimentos mais antigos empregados para a conservação do leite, é praticada há milhares de anos pelos seres humanos (TAMIME, 2002). Segundo ORDÓÑEZ et al. (2005), a fermentação deixou de servir apenas como método de conservação, transformando-se numa maneira de ampliar a gama de produtos lácteos.

A busca incessante por novos produtos levou a indústria de alimentos a perceber que os consumidores modernos estão cada vez mais preocupados com sua saúde e que desejam ingerir alimentos que sejam saudáveis e de preferência capazes de prevenir doenças (MATTILA-SANDHOLM et al., 2002). Produtos lácteos fermentados, contendo microrganismos probióticos, estão assumindo grande popularidade entre o público que procura por alimentos funcionais.

A acepção mais comumente aceita para probióticos os define como suplementos alimentares contendo microrganismos vivos, os quais afetam beneficamente a saúde do hospedeiro mediante melhoria do balanço microbiano intestinal (OUWEHAND et al., 1999; SHAH, 2000; HOLZAPFEL et al., 2001; SCHREZENMEIR e DE VRESE, 2001; MATTILA-SANDHOLM et al., 2002; TAMIME, 2002; ITSARANUWAT, SHAL-HADDAD e ROBINSON, 2003).

O segmento de probióticos no mercado foi dominado por produtos lácteos porque os consumidores já estão familiarizados com o fato de que os leites fermentados contêm microrganismos viáveis e os reconhecem como benéficos para a saúde, facilitando a recomendação da sua ingestão para o consumo de probióticos. Outra importante razão é a tecnológica, pois a maioria dos produtos lácteos já foram otimizados para a sobrevivência de microrganismos fermentativos, de forma que a tecnologia existente possa ser facilmente adaptada para garantir a sobrevivência das bactérias probióticas adicionadas (HELLER, 2001).

As principais espécies de bactérias probióticas utilizadas em produtos no mundo todo pertencem aos grupos Lactobacillus spp. (Lb. acidophilus, Lb. casei, $L b$. amylovorus, Lb. crispatus, $L b$. gallinarum, Lb. gasseri, Lb. johnsonii, Lb. plantarum, Lb. rhamnosus, Lb. salivarius, Lb. fermentum e $L b$. reuteri), Bifidobacterium spp. (Bif. adolescentis, Bif. animalis [Bif. lactis], Bif. bifidum, Bif. breve, Bif. infantis e Bif. longum) e Enterococcus spp. (Ent. faecalis e Ent. faecium) (ITSARANUWAT, SHAL-HADDAD e ROBINSON, 2003).

Esta revisão de literatura teve como objetivo apresentar os efeitos benéficos que a ingestão de probióticos pode oferecer à saúde e os inúmeros aspectos científicos e tecnológicos fundamentais para elaboração de produto lácteo probiótico. Apresenta, também, a utilização de bactérias ácido lácticas produtoras de exopolissacarídeos, bem como o desenvolvimento de novas classes de produtos funcionais envolvendo microrganismos probióticos em conjunto com compostos prebióticos (alimentos simbióticos).

\section{BENEFÍCIOS TERAPÊUTICOS RESULTANTES DO CONSUMO DE PRODUTOS PROBIÓTICOS}

A Organização das Nações Unidas para a Agricultura e a Alimentação, bem como a Organização Mundial da Saúde, já afirmavam em 2001 que existem evidências científicas adequadas indicando 0 potencial dos alimentos probióticos em fornecer benefícios à saúde, além da existência de linhagens seguras para o consumo humano (OTIENO, ASHTON e SHAH, 2005).

O epitélio intestinal intacto e a microbiota normal do intestino representam barreira ao movimento de bactérias patogênicas, antígenos e outras substâncias do lúmen intestinal para o sangue. Em indivíduos saudáveis, essa barreira é estável, protegendo o hospedeiro e assegurando a função normal do intestino. Quando a microbiota normal ou as células epiteliais são alteradas pela ação de antígenos da dieta, patógenos, substâncias químicas ou radiação surgem defeitos no mecanismo daquela barreira: 
a alteração na permeabilidade facilita a invasão do sangue por patógenos, antígenos estranhos e outras substâncias nocivas (GOMES e MALCATA, 1999). Entre as condições anormais que afetam a microbiota intestinal pode-se citar: o consumo excessivo de álcool, de alho ou de cebola, bem como a administração oral de antibióticos, que podem alterar drasticamente a população dos lactobacilos no intestino delgado. A reposição dessa microbiota "perdida" é um dos objetivos do consumo de produtos contendo microrganismos probióticos (ITSARANUWAT, SHAL-HADDAD e ROBINSON, 2003).

Dentre os benefícios à saúde, associados ao consumo de probióticos, que já se encontram bem documentados tem-se: 1) diminuição da frequência e da duração da diarreia associada aos antibióticos (Clostridium difficile), infecção por rotavírus, por quimioterapia, e em menor extensão da diarreia do viajante; 2) estimulação da imunidade humoral e celular; e 3) redução dos metabólitos indesejáveis, como amônia e enzimas pró-carcinogênicas no cólon. Além disso, existem evidências de outros efeitos: 1) redução da infecção por Helicobacter pylori; 2) diminuição dos sintomas alérgicos; 3) alívio da constipação; 4) alívio da síndrome do intestino irritado; 5) melhoria do metabolismo de minerais, principalmente a estabilidade e densidade dos ossos; 6) prevenção do câncer; e 7) redução das concentrações de colesterol e triglicerídeos no plasma sanguíneo (SCHREZENMEIR e DE VRESE, 2001).

MÖLLER e DE VRESE (2004) revisaram os efeitos probióticos das espécies Lactobacillus acidophilus (LA-5®) e Bifidobacterium lactis (BB-12®), que foram especialmente selecionadas pela Chr. Hansen para a elaboração de produtos lácteos probióticos. Existem evidências, com base em estudos científicos, de que essas linhagens conseguem proporcionar: balanceamento das instabilidades temporárias na microbiota intestinal, além de inibir a invasão e a colonização de microrganismos patogênicos indesejados; aumentar a concentração de ácidos orgânicos de cadeia curta, diminuindo o valor do pH; e diminuir a concentração de amônia, de indóis e de outras substâncias putrefativas no intestino. O consumo de probióticos por quatro semanas antes do tratamento com antibióticos reduziu a intensidade das complicações intestinais dos pacientes (diarreia ou constipação, dor abdominal, náusea, flatulência), quando comparados ao grupo controle (placebo). Houve menor número de casos de diarreia associada ao rotavírus em 55 crianças hospitalizadas, nos Estados Unidos da América, quando comparadas ao grupo que recebeu placebo. Somam-se a isso o aumento da produção de anticorpos e os efeitos anticarcinogênico (produção de substâncias que inibem a divisão e o crescimento das células do tumor) e anticolesterolêmico (desconjugação de sais biliares).

GOMES e MALCATA (1999) também fazem referência aos potenciais benefícios nutricionais e à saúde de alimentos preparados com bactérias probióticas, como aumento da digestibilidade, do valor nutricional e da utilização da lactose. Além disso, evidenciaram a ação hipocolesterolêmica pela produção de inibidores da síntese de colesterol e do uso do colesterol pela assimilação e precipitação com sais biliares desconjugados, além da imunomodulação, devido ao aumento na produção de macrófagos e estimulação ou produção de células supressoras e $\gamma$-interferon.

FOOKS, FULLER e GIBSON (1999), LEAHY et al. (2005) e PARVEZ et al. (2006) efetuaram revisões nas quais todos os efeitos benéficos dos probióticos foram novamente abordados e reafirmados. Contudo, convém ressaltar a necessidade da ingestão regular de células viáveis de bactérias probióticas de, no mínimo, $10^{6}$ UFC/g do produto para a obtenção dos efeitos benéficos (SHAH, 2000; VINDEROLA, BAILO e REINHEIMER, 2000; TALWALKAR e KAILASAPATHY, 2004b; ZACARCHENCO e MASSAGUER-ROIG, 2004; AKIN e GÜLER-AKIN, 2005; THAMER e PENNA, 2006).

\section{SELEÇÃO DE MICRORGANISMOS PROBIÓTICOS}

As bactérias do grupo ácido lácticas são organismos Gram-positivos, não esporulados e apresentam catalase e motilidade negativa. Além disso, não apresentam citocromos, são anaeróbicos ou aerotolerantes exigentes, tolerantes ao ácido e estritamente fermentativos, sendo o principal produto 
da fermentação o ácido láctico (HOLZAPFEL et al., 2001; LIN et al., 2006). Porém, as espécies frequentemente empregadas para a produção de iogurte (Streptococcus thermophilus e Lactobacillus delbrueckii subesp. bulgaricus) não sobrevivem à passagem pelo trato gastrointestinal humano e, com isso, não conseguem colonizar o intestino (SHAH, 2000).

A seleção de um microrganismo com propriedades probióticas exige a observação de três fatores principais: segurança, características funcionais e características tecnológicas. Quanto à segurança, aspectos como a origem (trato gastrointestinal de humanos saudáveis), não patogenicidade e resistência aos antibióticos devem ser verificados (MATTILA-SANDHOLM et al., 2002). As características funcionais e tecnológicas serão detalhadas a seguir.

\subsection{CARACTERÍSTICAS FUNCIONAIS}

Uma linhagem probiótica, considerando-se as características funcionais, deve apresentar as seguintes especificações: a) tolerância ao ácido e ao suco gástrico humano; b) tolerância à bile (importante característica para a sobrevivência no intestino delgado); c) aderência à superfície epitelial e persistência no trato gastrointestinal humano; d) imunoestimulação, mas não efeito pró-inflamatório; e) atividade antagonística em relação a patógenos, tais como Helicobacter pylori, Salmonella spp., Listeria monocytogenes e Clostridium difficile; e f) propriedades antimutagênicas e anticarcinogênicas (MATTILA-SANDHOLM et al., 2002; SCHILLINGER, GUIGAS e HOLZAPFEL, 2005; MARAGKOUDAKIS et al., 2006).

A capacidade que os lactobacilos exibem de resistir ao ácido é atribuída à presença de gradiente constante entre o $\mathrm{pH}$ extracelular e o $\mathrm{pH}$ citoplasmático. No momento em que o $\mathrm{pH}$ interno atinge $\mathrm{o}$ valor limite, as funções celulares são inibidas e a célula morre. A enzima $F_{0} F_{1}$-ATPase é utilizada pelos organismos Gram-positivos para a proteção contra condições ácidas. A $F_{0} F_{1}$-ATPase, enzima formada por múltiplas subunidades, consiste numa porção catalítica $\left(F_{1}\right)$, que incorpora as subunidades $\alpha, \beta$, $\gamma, \delta$ e $\varepsilon$ para a hidrólise do ATP, e uma porção integrada à membrana $\left(F_{0}\right)$, que inclui as subunidades $a, b$ e $c$, funcionando como canal membranoso para a translocação de prótons. O papel da $F_{0} F_{1^{-}}$ ATPase em organismos isentos de cadeia respiratória é gerar a força próton motiva, mediante expulsão de prótons. Assim, imagina-se que a $F_{0} F_{1}$-ATPase pode aumentar o $\mathrm{pH}$ intracelular quando a célula se encontra em pH extracelular baixo. Inclusive, a $F_{0} F_{1}$-ATPase é induzida em $\mathrm{pH}$ baixo, e sua regulação parece ocorrer no nível transcricional (CORCORAN et al., 2005). Por não realizarem fosforilação oxidativa, a força próton motiva nos microrganismos fermentativos não é gerada naturalmente. Em função de muitas reações celulares, como motilidade e transporte, requererem a energia de força próton motiva, a $F_{0} F_{1}$-ATPase precisa bombear prótons para fora da célula, gerando a força próton motiva que será usada nessas funções celulares (MADIGAN, MARTINKO e PARKER, 2004). Assim, a célula consegue se proteger em ambientes ácidos, pois os prótons que penetrarem através da membrana serão novamente conduzidos para fora da célula. O mais importante é que, além de permitir a sobrevivência, esse mecanismo vai gerar energia para a célula. Entretanto, conforme observado por CORCORAN et al. (2005), a $F_{0} F_{1}$-ATPase necessita de ATP para a expulsão de $\boldsymbol{H}^{+}$da célula, mantendo, assim, a homeostase do $\mathrm{pH}$ e a viabilidade celular. Com isto, a célula precisará de suporte de ATP, que será hidrolisado durante a expulsão dos prótons pela enzima $F_{0} F_{1}$-ATPase. Caso contrário, a sobrevivência em pH extracelular baixo estará comprometida.

A bile, solução aquosa de coloração verde-amarelada, tem como principais constituintes ácidos biliares, colesterol, fosfolipídeos e o pigmento biliverdina. É sintetizada nos hepatócitos pericentrais do fígado e liberada no duodeno logo após a ingestão de alimentos. A bile funciona como detergente biológico que emulsifica e solubiliza os lipídios e, com isso, desempenha papel importante na digestão das gorduras. Essa mesma propriedade detergente da bile é a responsável pela sua atividade antimicrobiana, agindo primariamente através da dissolução da membrana plasmática das bactérias. O fígado, inicialmente, transforma moléculas de colesterol em moléculas de ácidos biliares, mediante 
incorporação de grupamento carboxílico. Em seguida, para aumentar a solubilidade do núcleo esteroide, hidrofóbico, o ácido biliar sofre reação de conjugação com um aminoácido (glicina ou taurina). A união ocorre por meio de ligação amida, resultando em um $\mathrm{N}$-acil amidato. Na sequência, o sal biliar pode ser secretado. A molécula resultante é anfótera e pode solubilizar lipídios pela formação de micelas. Para resistirem à bile, as bactérias probióticas apresentam enzimas do grupo sal biliar hidrolase (EC 3.5.1.24) que catalisam a reação de desconjugação do sal biliar, hidrolisando a ligação amida entre o ácido biliar e o aminoácido. Dessa forma, o aminoácido é liberado do núcleo esteroide e o ácido biliar desconjugado precipita em pH baixo (BEGLEY, HILL e GAHAN, 2006). As evidências sugerem que o efeito hipocolesterolêmico das bactérias probióticas resida, justamente, na desconjugação dos sais biliares: o fígado precisaria transformar mais moléculas de colesterol em sais biliares, diminuindo o teor de colesterol do plasma sanguíneo.

A aderência e a colonização são atributos muito importantes para a funcionalidade dos probióticos, principalmente quando se considera os efeitos que requerem a estimulação dos enterócitos intestinais. A associação mais íntima com a mucosa intestinal geralmente envolve a aderência da bactéria às células epiteliais, caso contrário a bactéria probiótica pode não influenciar os parâmetros fisiológicos. Os estudos realizados com linhagens exógenas, inclusive aquelas que mostraram boa capacidade de aderência in vitro, indicaram que elas geralmente não persistem no intestino. Mesmo que ocorra alguma aderência, essa não parece ser acompanhada pela colonização, já que a população de probióticos cai para níveis indetectáveis nas fezes quando o consumo do produto é interrompido. A linhagem Lactobacillus acidophilus NCMF consegue aderir às células epiteliais mediante mecanismo mediado por proteína, mas outras espécies podem empregar carboidratos, como exopolissacarídeos (SANDERS e KLAENHAMMER, 2001).

Segundo KIRJAVAINEN et al. (1998), a adesão bacteriana baseia-se, inicialmente, em interações físicas não específicas entre duas superfícies, que permitem interações específicas entre adesinas (geralmente proteínas) e os receptores complementares. O muco que cobre as células epiteliais do intestino constitui importante sítio para adesão e colonização bacteriana. Esse muco está continuamente sendo degradado e, assim, novas glicoproteínas, chamadas mucinas (principais constituintes do muco), são constantemente secretadas. O resultado disso é que bactérias que conseguem aderir ao muco, mas que são incapazes de alcançar as células epiteliais, serão removidas da superfície da mucosa junto com a mucina degradada e excretadas com o restante do conteúdo do lúmen. Essa representa possível explicação para o perfil de colonização transiente, característico para a maioria das bactérias probióticas. LIN et al. (2006) avaliaram oito produtos comerciais, contendo bactérias ácido lácticas, mediante contagens de células viáveis, verificação da tolerância ao ácido e à bile e capacidade de adesão ao epitélio intestinal humano das linhagens isoladas. Os resultados evidenciaram que a maioria das linhagens era incapaz de aderir às células epiteliais do intestino humano, ou aderiam muito fracamente, indicando que a função probiótica desses produtos pode ser bem reduzida.

A atividade antimicrobiana é uma das formas empregadas pelas bactérias probióticas para excluir, competitivamente, ou inibir a atividade das bactérias patogênicas no intestino. Entre os compostos antimicrobianos produzidos por bactérias probióticas estão ácidos orgânicos (ácido láctico e acético), peróxido de hidrogênio (nos ambientes em que oxigênio está presente), diacetil, $\beta$-hidroxipropionaldeído (produzido por Lactobacillus reuteri), além de peptídeos (ou proteínas) bacteriostáticos ou bactericidas. Bacteriocinas, compostos proteicos produzidos por bactérias, exibem atividade bacteriostática ou bactericida sobre bactérias susceptíveis. Estudos in vitro mostraram que a maioria das linhagens de Lactobacillus produz, frequentemente, bacteriocinas que destroem espécies intimamente relacionadas. Como exemplo, a linhagem Lactobacillus acidophilus NCMF produz a bacteriocina denominada lactacin $B$, que não apresenta ação contra patógenos (SANDERS e KLAENHAMMER, 2001). MAKRAS e DE VUYST (2006) observaram que as linhagens de Bifidobacterium testadas exibiram forte atividade antibacteriana para Salmonella 
enterica sorovar Typhimurium SL1344 e Escherichia coli C1845. Segundo tais autores, essa atividade tem origem na produção de ácidos orgânicos, em particular ácido láctico e ácido acético. Geralmente, esses ácidos orgânicos apresentam forte atividade inibitória contra bactérias Gramnegativas, pois a forma não dissociada do ácido orgânico penetra na célula bacteriana e se dissocia no citoplasma. A eventual queda do $\mathrm{pH}$ interno ou a acumulação intracelular da forma ionizada do ácido orgânico conduz à morte do patógeno. Outra importante característica funcional das bactérias probióticas é a imunomodulação. Conforme OUWEHAND et al. (1999) para que o microrganismo probiótico consiga influenciar o sistema imune é necessário que a bactéria ative as células do tecido linfoide, associado ao intestino. Os probióticos podem afetar essas células pelas interações entre o tecido linfoide e o microrganismo intacto, seus fragmentos ou metabólitos produzidos in situ. O consumo das linhagens adesivas Lactobacillus johnsonii Lj1 e Bifidobacterium lactis Bb12 aumentou a fagocitose de Escherichia coli in vitro. Uma preparação, contendo esses dois microrganismos em conjunto com Streptococcus thermophilus, aumentou o nível de IgA contra Salmonella.

\subsection{CARACTERÍSTICAS TECNOLÓGICAS}

Dentre as características tecnológicas que as candidatas a bactérias probióticas deverão exibir, as mais importantes são: a) propriedades sensoriais agradáveis; b) resistência aos bacteriófagos; c) viabilidade durante o processamento; e d) estabilidade no produto e durante a estocagem (MATTILASANDHOLM et al., 2002).

Em relação ao sabor do produto fermentado é preciso mencionar que algumas espécies de bactérias probióticas são homofermentativas (produzem apenas ácido láctico), enquanto outras são heterofermentativas (produzem ácido láctico e outros ácidos orgânicos). Por exemplo, as bifidobactérias são heterofermentativas e produzem mistura de ácido acético e ácido láctico na proporção de 3:2, respectivamente. $\mathrm{O}$ ácido acético vai proporcionar sabor desagradável de vinagre. Além disso, as bactérias probióticas se multiplicam muito lentamente no leite (por apresentarem baixa atividade proteolítica), gerando pouco ácido láctico, o que aumenta o tempo de fermentação. Assim, as linhagens probióticas não são empregadas sozinhas, mas em conjunto com a cultura starter do iogurte (Streptococcus thermophilus e Lactobacillus delbrueckii subesp. bulgaricus) (ORDÓÑEZ et al., 2005; SHAH, 2000). A combinação da cultura starter com as bactérias probióticas permite obter produto final com as características ideais de textura, $\mathrm{pH}$, aroma e sabor. Mas, conforme mencionado por SHAH (2000), o Lactobacillus delbrueckii subesp. bulgaricus continua produzindo ácido láctico durante a estocagem sob refrigeração. A indústria chama esse fenômeno de pós-acidificação. O ácido, produzido durante a estocagem refrigerada, causa diminuição na viabilidade das bactérias probióticas. Portanto, recomenda-se empregar apenas Streptococcus thermophilus em conjunto com as bactérias probióticas. Nesse caso, mesmo sendo menos proteolítico do que L. delbrueckii subesp. bulgaricus, S. thermophilus torna-se o principal responsável pela fermentação. A viabilidade das bactérias probióticas também depende da linhagem utilizada, da interação entre as espécies presentes, da acidez final do produto e das concentrações de ácido láctico e acético. Outros fatores que interferem na viabilidade são: a disponibilidade de nutrientes e de promotores (ou inibidores) de crescimento; a concentração de açúcares (pressão osmótica); o teor de oxigênio dissolvido e a permeabilidade de oxigênio através da embalagem; a quantidade de inóculo; a temperatura de incubação; o tempo de fermentação e a temperatura de estocagem. Entretanto, os principais fatores que levam à perda de viabilidade são a redução do pH do meio e a acumulação de ácidos orgânicos como resultado do crescimento e da fermentação. As bifidobactérias são anaeróbicas por natureza, portanto elevado teor de oxigênio pode afetar seu crescimento e viabilidade. A acumulação de peróxido de hidrogênio é facilitada pelo fato dos lactobacilos não apresentarem a enzima catalase, mas a concentração de peróxido de hidrogênio produzida pelos starters parece não ser suficiente para afetar diretamente as células presentes no 
produto. No entanto, o peróxido de hidrogênio pode reagir com outros compostos e produzir substâncias inibidoras (SHAH, 2000; VINDEROLA, MOCCHIUTTI e REINHEIMER, 2002b; TALWALKAR e KAILASAPATHY, 2003; DONKOR et al., 2006). As bifidobactérias, estritamente anaeróbias, geralmente são consideradas mais vulneráveis aos efeitos deletérios do oxigênio do que o Lactobacillus acidophilus (microaerófilo) (TALWALKAR e KAILASAPATHY, 2004a).

Para lidar com o problema da permeabilidade das embalagens plásticas ao oxigênio, uma das opções é o emprego de embalagens de vidro que são menos permeáveis. Contudo, considerando as dificuldades inerentes a essa estratégia pode-se trabalhar com a adição de ácido ascórbico que atua como removedor de oxigênio. Além do ácido ascórbico, a adição de L-cisteína mostrou-se efetiva para o aumento da viabilidade das bifidobactérias (na concentração de $0,05 \%$ no leite). A cisteína, aminoácido sulfurado, pode servir como fonte de nitrogênio (fator de crescimento), bem como reduzir o potencial redox do meio - ambos os mecanismos favorecem o crescimento das espécies de bifidobactérias (SHAH, 2000). DAVE e SHAH (1998) mostraram que a adição de soro de queijo em pó e de concentrado de proteínas do soro pode afetar consideravelmente a viabilidade das bactérias, servindo como fontes de peptídeos e aminoácidos em função do tratamento térmico do leite durante o processamento do iogurte. As proteínas do soro são ricas em aminoácidos sulfurados, os quais são liberados durante o tratamento térmico e, assim, poderão diminuir o potencial redox do meio. Conforme relatado por TALWALKAR e KAILASAPATHY (2004a), as proteínas do soro também podem atuar como sistema tampão, evitando mudanças bruscas no $\mathrm{pH}$.

Alguns aditivos comumente utilizados pela indústria de laticínios são: sais, açúcares, frutas, adoçantes, corantes, aromatizantes, nisina, natamicina e lisozima. Em estudo realizado por VINDEROLA et al. (2002a) foi avaliado o efeito desses aditivos no crescimento das culturas starters e probióticas. Os resultados mostraram que, em geral, as bactérias probióticas são mais resistentes aos aditivos do que as culturas starters. Compostos como $\mathrm{KCl}$, adoçantes (acessulfame e aspartame), compostos do aroma (diacetil, acetaldeído e acetoína), natamicina, aromatizantes (essências de morango, baunilha, pêssego e banana) e agentes corantes-aromatizantes (pêssego) não influenciaram o crescimento das linhagens nas concentrações comumente utilizadas na indústria de laticínios. O efeito de outras substâncias sobre o crescimento das culturas starters e probióticas dependeu da linhagem empregada. Assim, propuseram que a tolerância das culturas starters e das bactérias probióticas aos aditivos deveria constituir critério de seleção para possibilitar a melhor combinação de linhagens, melhorando o desempenho no crescimento e a viabilidade celular durante o processo industrial e a estocagem do produto.

\section{PRODUÇÃO DE EXOPOLISSACARÍDEOS POR BACTÉRIAS ÁCIDO LÁCTICAS}

As bactérias do grupo ácido lácticas, capazes de sintetizar exopolissacarídeos, ganharam considerável atenção da indústria de laticínios em função da sua potencial aplicação como agentes espessantes e emulsificantes. Com o aumento da popularidade dos produtos alimentícios "naturais" sem a adição de aditivos, o uso de linhagens de bactérias ácido lácticas produtoras de exopolissacarídeos pode resultar em produto final seguro, natural e saudável. Além disso, apresentará melhor textura e maior estabilidade, gerando impacto muito importante no desenvolvimento de novos produtos (LIN e CHANG CHIEN, 2007).

A habilidade de sintetizar polissacarídeos encontra-se amplamente difundida entre as bactérias. Microrganismos podem sintetizar polissacarídeos de armazenamento, como o glicogênio (localizado no citoplasma) e polissacarídeos estruturais, constituintes da parede celular, como peptidioglicano e ácidos lipoteicoicos (bactérias Gram-positivas) e lipopolissacarídeos (bactérias Gram-negativas). Além disso, algumas bactérias podem secretar camadas de polissacarídeos em sua superfície que, juntamente com algumas glicoproteínas, são agrupados sob o termo de "glicocálice". Esses polímeros 
exocelulares constam de polissacarídeos capsulares, os quais formam uma camada (ou cápsula) coesiva covalentemente ligada à superfície da célula, e de exopolissacarídeos, que formam camada viscosa fracamente ligada à superfície da célula ou secretada no ambiente (BROADBENT et al., 2003; RUAS-MADIEDO e REYES-GAVILÁN, 2005).

Na indústria de alimentos, exopolissacarídeos produzidos por bactérias do grupo ácido lácticas ou por outras bactérias são usados como agentes espessantes, estabilizantes ou emulsificantes para modificar as propriedades reológicas e de textura dos produtos. O uso de linhagens produtoras de exopolissacarídeos recebeu maior atenção nos últimos anos por se tratar de fonte natural de bioespessantes alimentícios (DE VUYST et al., 2003; RUAS-MADIEDO e REYES-GAVILÁN, 2005; SVENSSON et al., 2005). LAWS e MARSHALL (2001) mencionaram que a ação dos exopolissacarídeos, ligando as bactérias mucoides à matriz proteica resulta na ampliação do comportamento viscoso do produto. Outra característica interessante é que alguns exopolissacarídeos produzidos por bactérias ácido lácticas parecem ser benéficos para a saúde humana, mediante efeitos hipocolesterolêmico e prebiótico, imunomodulação (incluindo ativação da atividade de macrófagos e linfócitos) e atividade anticarcinogênica (RUAS-MADIEDO e REYESGAVILÁN, 2005; LIN e CHANG CHIEN, 2007).

Dependendo da sua composição química, o exopolissacarídeo pode ser classificado como homopolissacarídeo (contém um único tipo de monossacarídeo); e heteropolissacarídeo (formado por unidades repetidas de diferentes monossacarídeos). Os homopolissacarídeos apresentam a cadeia principal com graus variáveis de ramificações e sítios de ligação, os quais diferem entre as linhagens bacterianas. Já os heteropolissacarídeos geralmente contêm a combinação de D-glicose, D-galactose e L-ramnose, ou em alguns poucos casos $\mathrm{N}$-acetilglicosamina, $\mathrm{N}$-acetilgalactosamina, fucose, ácido glucurônico e outros substituintes (fosfato, acetil e glicerol) (BROADBENT et al., 2003; RUAS-MADIEDO e REYES-GAVILÁN, 2005).

As principais linhagens de bactérias do grupo ácido lácticas capazes de produzir exopolissacarídeos pertencem aos gêneros Streptococcus, Lactobacillus, Lactococcus, Leuconostoc e Pediococcus. Também já se verificou que algumas linhagens do gênero Bifidobacterium podem produzir esses biopolímeros (RUAS-MADIEDO e REYES-GAVILÁN, 2005).

O tempo de fermentação constitui um dos parâmetros ambientais mais críticos que afetam o teor, a massa molar e a composição de açúcares do exopolissacarídeo (LIN e CHANG CHIEN, 2007). Dependendo da linhagem, a síntese de exopolissacarídeo pelas bactérias ácido lácticas pode ou não estar associada ao crescimento. A produção de exopolissacarídeo depende da composição do meio (como fonte de carbono/nitrogênio), condições de crescimento da cultura ( $\mathrm{pH}$, temperatura, concentração de oxigênio) e do tipo de linhagem utilizada. A relação carbono/nitrogênio e a limitação dessas fontes de nutrientes também influenciam a produção diferencial de exopolissacarídeos (mais de um polímero) pela mesma linhagem (RUAS-MADIEDO, ALTING e ZOON, 2005). No caso do Streptococcus thermophilus também se deve dar atenção para a organização genética dos grupos de genes eps e às enzimas envolvidas na biossíntese e interconversão dos nucleotídeos de açúcares (precursores dos exopolissacarídeos), ou na ligação das diferentes moléculas de açúcar (glicosiltransferases) (JOLLY e STINGELE, 2001; DEGEEST, MOZZI e VUYST, 2002).

\section{PREBIÓTICOS E SIMBIÓTICOS}

Um prebiótico, ingrediente alimentício não digerível, afeta beneficamente quem o ingere pela estimulação seletiva do crescimento e/ou da atividade de uma ou de número limitado de espécie(s) de bactérias no cólon. O conceito é bastante semelhante ao da fibra alimentar, a não ser pelo aspecto da seletividade em relação às espécies bacterianas. Essa seletividade já foi observada para as bifidobactérias, as quais podem ser estimuladas pela ingestão de substâncias como 
frutooligossacarídeos, inulina, lactulose, amido resistente, oligossacarídeos transgalactosilados e oligossacarídeos da soja (FOOKS, FULLER e GIBSON, 1999; SCHREZENMEIR e DE VRESE, 2001; ITSARANUWAT, SHAL-HADDAD e ROBINSON, 2003).

Usa-se o termo simbiótico quando o produto contém ambos, prebióticos e probióticos. A denominação deveria ser reservada para os produtos nos quais o composto prebiótico favorece seletivamente o probiótico associado (FOOKS, FULLER e GIBSON, 1999; SCHREZENMEIR e DE VRESE, 2001). Porém, ITSARANUWAT, SHAL-HADDAD e ROBINSON (2003) acreditam que, como o mesmo prebiótico pode estimular a atividade de certo número de espécies endógenas de bifidobactérias no cólon ao mesmo tempo, seria desnecessário criar termo especial para o sistema pre/probiótico. Outra vantagem da combinação de prebióticos e probióticos pode ser observada no estudo realizado por OTIENO, ASHTON e SHAH (2005). Microrganismos probióticos apresentam enzimas como $\beta$ glicosidase, $\beta$-galactosidase e $\alpha$-galactosidase, as quais desempenham papel importante na hidrólise dos glicosídeos isoflavonas presentes na soja, resultando nas formas agliconas biodisponíveis no leite de soja fermentado. Além disso, WANG, YU e CHOU (2006) verificaram aumento significativo na atividade antioxidante do leite de soja fermentado com bactérias ácido lácticas e bifidobactérias.

\section{CONSIDERAÇÕES FINAIS}

A elaboração de produtos lácteos fermentados por microrganismos probióticos depende do conhecimento de diversas áreas da ciência e tecnologia de alimentos. O principal objetivo da indústria é agregar valor mediante obtenção de produto que, além de nutritivo, seja capaz de beneficiar a saúde de quem o ingere. Assim, é importante que todos os requisitos para a fabricação de produto lácteo probiótico em sua máxima funcionalidade sejam observados para que o consumidor possa usufruir de alimento que apresente as alegadas propriedades benéficas. Novas pesquisas deverão ser realizadas de forma a ampliar ainda mais os conhecimentos e o desenvolvimento de produtos diferenciados, bem como investigar novas linhagens de microrganismos probióticos com potencial de sintetizar exopolissacarídeos para aplicação como agentes espessantes e emulsificantes, gerando impacto muito importante no desenvolvimento de novos produtos.

\section{ABSTRACT \\ SCIENTIFIC AND TECHNOLOGICAL ASPECTS OF USING PROBIOTIC CULTURES TO PRODUCE FERMENTED DAIRY PRODUCTS: REVIEW}

The present work by means of a literature review had the aim of presenting the health benefits of probiotic dairy products ingestion and the countless scientific and technological aspects related to their processing. Moreover, it points out the utilization of exopolysaccharide-producing strains of lactic acid bacteria, as well as the development of new classes of functional products combined to probiotic microorganisms and prebiotics compounds (synbiotic foods). Selection of a microorganism with probiotic properties requires the observation of three factors: safety, functional characteristics and technological characteristics. Therefore, when observed all the approached aspects it will be possible to obtain a probiotic product with the quality required and in its maximum functionality.

KEY-WORDS: FERMENTATION; PROBIOTICS; PREBIOTICS; EXOPOLYSACCHARIDES; FUNCTIONAL FOODS.

\section{REFERÊNCIAS}

1 AKIN, M.S.; GÜLLER-AKIN, M.B. Effect of different incubation temperatures on the microflora, chemical composition and sensory characteristics of bio-yogurt. Italian Journal of Food Science, v. 17, n. 1, p. 6774, 2005. 
2 BEGLEY, M.; HILL, C.; GAHAN, C.G.M. Bile salt hydrolase activity in probiotics. Applied and Environmental Microbiology, v. 72, n. 3, p. 1729-1738, 2006.

3 BROADBENT, J.R.; MCMAHON, D.J.; WELKER, D.L.; OBERG, C.J.; MOINEAU, S. Biochemistry, genetics, and applications of exopolysaccharide production in Streptococcus thermophilus: a review. Journal of Dairy Science, v. 86, n. 2, p. 407-423, 2003.

4 CORCORAN, B.M.; STANTON, C.; FITZGERALD, G.F.; ROSS, R.P. Survival of probiotic Lactobacilli in acidic environments is enhanced in the presence of metabolizable sugars. Applied and Environmental Microbiology, v. 71, n. 6, p. 3060-3067, 2005.

5 DAVE, R.I.; SHAH, N.P. Ingredient supplementation effects on viability of probiotic bacteria in yogurt. Journal of Dairy Science, v. 81, n. 11, p. 2804-2816, 1998.

6 DEGEEST, B.; MOZZI, F.; DE VUYST, L. Effect of medium composition and temperature and pH changes on exopolysaccharide yields and stability during Streptococcus thermophilus LY03 fermentations. International Journal of Food Microbiology, v. 79, n. 3, p. 161-174, 2002.

7 DE VUYST, L.; ZAMFIR, M.; MOZZI, F.; ADRIANY, T.; MARSHALL, V.; DEGEEST, B.; VANINGELGEM, F. Exopolysaccharide-producing Streptococcus thermophilus strains as functional starter cultures in the production of fermented milks. International Dairy Journal, v. 13, n. 8, p. 707-717, 2003.

8 DONKOR, O.N.; HENRIKSSON, A.; VASILJEVIC, T.; SHAH, N.P. Effect of acidification on the activity of probiotics in yoghurt during cold storage. International Dairy Journal, v. 16, n. 10, p. 1181-1189, 2006.

9 FOOKS, L.J.; FULLER, R.; GIBSON, G.R. Prebiotics, probiotics and human gut microbiology. International Dairy Journal, v. 9, n. 1, p. 53-61, 1999.

10 GOMES, A.M.P.; MALCATA, F.X. Bifidobacterium spp. and Lactobacillus acidophilus: biological, biochemical, technological and therapeutical properties relevant for use as probiotics. Trends in Food Science \& Technology, v. 10, n. 4-5, p. 139-157, 1999.

11 HELLER, K.J. Probiotic bacteria in fermented foods: product characteristics and starter organisms. American Journal of Clinical Nutrition, v. 73, suplem., p. 374S-379S, 2001.

12 HOLZAPFEL, W.H.; HABERER, P.; GEISEN, R.; BJÖRKROTH, J.; SCHILLINGER, U. Taxonomy and important features of probiotic microorganisms in food and nutrition. American Journal of Clinical Nutrition, v. 73, supl., p. 365S-373S, 2001.

13 ITSARANUWAT, P.; SHAL-HADDAD, K.; ROBINSON, R.K. The potential therapeutic benefits of consuming 'health-promoting' fermented dairy products: a brief update. International Journal of Dairy Technology, v. 56, n. 4 , p. $203-210,2003$.

14 JOLLY, L.; STINGELE, F. Molecular organization and functionality of exopolysaccharide gene clusters in lactic acid bacteria. International Dairy Journal, v. 11, n. 9, p. 733-745, 2001.

15 KIRJAVAINEN, P.V.; OUWEHAND, A.C.; ISOLAURI, E.; SALMINEN, S.J. The ability of probiotic bacteria to bind to human intestinal mucus. FEMS Microbiology Letters, v. 167, n. 2, p. 185-189, 1998.

16 LAWS, A.P.; MARSHALL, V.M. The relevance of exopolysaccharides to the rheological properties in milk fermented with ropy strains of lactic acid bacteria. International Dairy Journal, v. 11, n. 9, p. 709-721, 2001.

17 LEAHY, S.C.; HIGGINS, D.G.; FITZGERALD, G.F.; VAN SINDEREN, D. Getting better with bifidobacteria. Journal of Applied Microbiology, v. 98, n. 6, p. 1303-1315, 2005.

18 LIN, T.Y.; CHANG CHIEN, M.-F. Exopolysaccharides production as affected by lactic acid bacteria and fermentation time. Food Chemistry, v. 100, n. 4, p. 1419-1423, 2007.

19 LIN, W.-H.; HWANG, C.-F.; CHEN, L.-W.; TSEN, H.-Y. Viable counts, characteristic evaluation for commercial lactic acid bacteria products. Food Microbiology, v. 23, n. 1, p. 74-81, 2006.

20 MADIGAN, M.T.; MARTINKO, J.M.; PARKER, J. Microbiologia de Brock. 10. ed. São Paulo: Prentice Hall, 2004. $608 \mathrm{p}$. 
21 MAKRAS, L.; DE VUYST, L. The in vitro inhibition of Gram-negative pathogenic bacteria by bifidobacteria is caused by the production of organic acids. International Dairy Journal, v. 16, n. 9, p. 1049-1057, 2006.

22 MARAGKOUDAKIS, P.A.; ZOUMPOPOULOU, G.; MIARIS, C.; KALANTZOPOULOS, G.; POT, B.; TSAKALIDOU, E. Probiotic potential of Lactobacillus strains isolated from dairy products. International Dairy Journal, v. 16, n. 3, p. 189-199, 2006.

23 MATTILA-SANDHOLM, T.; MYLLÄRINEN, P.; CRITTENDEN, R.; MOGENSEN, G.; FONDÉN, R.; SAARELA, M. Technological challenges for future probiotic foods. International Dairy Journal, v. 12, n. 2-3, p. 173182, 2002.

24 MÖLLER, C.; DE VRESE, M. Review: probiotic effects of selected acid bacteria. Milchwissenschaft, v. 59, n. 11-12, p. 597-601, 2004.

25 ORDÓÑEZ, J.A.; RODRÍGUEZ, M.I.C.; ÁLVAREZ, L.F.; SANZ, M.L.G.; MINGUILLÓN, G.G.F.; PERALES, L.H.; CORTECERO, M. D. S. Tecnologia de alimentos: alimentos de origem animal. Porto Alegre: Artmed, 2005. 279 p. v. 2.

26 OTIENO, D.O.; ASHTON, J.F.; SHAH, N.P. Stability of $\beta$-glucosidase activity produced by Bifidobacterium and Lactobacillus spp. in fermented soymilk during processing and storage. Journal of Food Science, v. 70, n. 4, p. M236-M241, 2005.

27 OUWEHAND, A.C.; KIRJAVAINEN, P.V.; SHORTT, C.; SALMINEN, S. Probiotics: mechanisms and established effects. International Dairy Journal, v. 9, n. 1, p. 43-52, 1999.

28 PARVEZ, S.; MALIK, K.A.; AH KANG, S.; KIM, H.-Y. Probiotics and their fermented food products are beneficial for health. Journal of Applied Microbiology, v. 100, n. 6, p. 1171-1185, 2006.

29 RUAS-MADIEDO, P.; ALTING, A.C.; ZOON, P. Effect of exopolysaccharides and proteolytic activity of Lactococcus lactis subsp. cremoris strains on the viscosity and structure of fermented milks. International Dairy Journal, v. 15, n. 2, p. 155-164, 2005.

30 RUAS-MADIEDO, P.; REYES-GAVILÁN, C.G.D.L. Methods for the screening, isolation, and characterization of exopolysaccharides produced by lactic acid bacteria. Journal of Dairy Science, v. 88, n. 3, p. 843-856, 2006.

31 SANDERS, M.E.; KLAENHAMMER, T.R. The scientific basis of Lactobacillus acidophilus NCFM functionality as a probiotic. Journal of Dairy Science, v. 84, n. 2, p. 319-331, 2001.

32 SCHILLINGER, U.; GUIGAS, C.; HOLZAPFEL, H. In vitro adherence and other properties of lactobacilli used in probiotic yoghurt-like products. International Dairy Journal, v. 15, n. 12, p. 1289-1297, 2005.

33 SCHREZENMEIR, J.; DE VRESE, M. Probiotics, prebiotics, and synbiotics - approaching a definition. American Journal of Clinical Nutrition, v. 73, suplem., p. 361S-364S, 2001.

$34 \mathrm{SHAH}$, N.P. Probiotic bacteria: selective enumeration and survival in dairy foods. Journal of Dairy Science, v. 83, n. 4 , p. $894-907,2000$.

35 SVENSSON, M.; WAAK, E.; SVENSSON, U.; RADSTRÖM, P. Metabolically improved exopolysaccharide production by Streptococcus thermophilus and its influence on the rheological properties of fermented milk. Applied and Environmental Microbiology, v. 71, n. 10, p. 6398-6400, 2005.

36 TALWALKAR, A.; KAILASAPATHY, K. A review of oxygen toxicity in probiotic yogurts: influence on the survival of probiotic bacteria and protective techniques. Comprehensive Reviews in Food Science and Food Safety, v. 3, n. 3, p. 117-124, 2004a.

37 TALWALKAR, A.; KAILASAPATHY, K. Comparison of selective and differential media for the accurate enumeration of strains of Lactobacillus acidophilus, Bifidobacterium spp. and Lactobacillus casei complex from commercial yoghurts. International Dairy Journal, v. 14, n. 2, p. 143-149, 2004b.

38 TALWALKAR, A.; KAILASAPATHY, K. Metabolic and biochemical responses of probiotic bacteria to oxygen. Journal of Dairy Science, v. 86, n. 8, p. 2537-2546, 2003.

39 TAMIME, A.Y. Fermented milks: a historical food with modern applications - a review. European Journal of Clinical Nutrition, v. 56, supl. 4, p. S2-S15, 2002. 
40 THAMER, K.G.; PENNA, A.L.B. Caracterização de bebidas lácteas funcionais fermentadas por probióticos e acrescidas de prebiótico. Ciência e Tecnologia de Alimentos, v. 26, n. 3, p. 589-595, 2006.

41 VINDEROLA, C.G.; BAILO, N.; REINHEIMER, J.A. Survival of probiotic microflora in Argentinian yoghurts during refrigerated storage. Food Research International, v. 33, n. 2, p. 97-102, 2000.

42 VINDEROLA, C.G.; COSTA, G.A.; REGENHARDT, S.; REINHEIMER, J.A. Influence of compounds associated with fermented dairy products on the growth of lactic acid starter and probiotic bacteria. International Dairy Journal, v. 12, n. 7, p. 579-589, 2002a.

43 VINDEROLA, C.G.; MOCCHIUTTI, P.; REINHEIMER, J.A. Interactions among lactic acid starter and probiotic bacteria used for fermented dairy products. Journal of Dairy Science, v. 85, n. 4, p. 721-729, 2002 b.

44 WANG, Y.-C.; YU, R.-C.; CHOU, C.-C. Antioxidative activities of soymilk fermented with lactic acid bacteria and bifidobacteria. Food Microbiology, v. 23, n. 2, p. 128-135, 2006.

45 ZACARCHENCO, P.B.; MASSAGUER-ROIG, S. Avaliação sensorial, microbiológica e de pós-acidificação durante a vida-de-prateleira de leites fermentados contendo Streptococcus thermophilus, Bifidobacterium longum e Lactobacillus acidophilus. Ciência e Tecnologia de Alimentos, v. 24, n. 4, p. 674-679, 2004. 